\title{
DÜBLIN
}

Technological University Dublin

ARROW@TU Dublin

\section{Growth Inhibition of Common Food Spoilage and Pathogenic Microorganisms in the Presence of Brown Seaweed Extracts}

\author{
Shilpi Gupta \\ Technological University Dublin, shilpi.19may@gmail.com \\ Sabrina Cox \\ Technological University Dublin, sabrina.cox@tudublin.ie \\ Gaurav Rajauria \\ Technological University Dublin, gaurav.rajauria@tudublin.ie
}

See next page for additional authors

Follow this and additional works at: https://arrow.tudublin.ie/schfsehart

Part of the Food Biotechnology Commons, Food Chemistry Commons, and the Food Microbiology

Commons

\section{Recommended Citation}

Gupta, S., Cox, N., Rajauria, G., Jaiswal, A.K. \& Abu-Ghannam, N. (2010). Modelling the growth inhibition of common food spoilage and pathogenic micro-organisms in the presence of brown seaweed extracts.

Food and Bioprocess Technology, DOI: 10.1007/s11947-010-0502-6

This Article is brought to you for free and open access by the School of Food Science and Environmental Health at ARROW@TU Dublin. It has been accepted for inclusion in Articles by an authorized administrator of ARROW@TU

Dublin. For more information, please contact arrow.admin@tudublin.ie, aisling.coyne@tudublin.ie, gerard.connolly@tudublin.ie.

Funder: Irish Government under the Technological Sector Research Scheme (Strand III) of the National

Development Plan

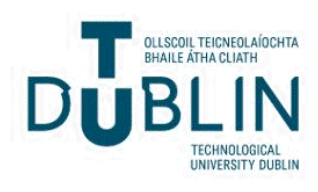




\section{Authors}

Shilpi Gupta, Sabrina Cox, Gaurav Rajauria, Amit Jaiswal, and Nissreen Abu-Ghannam

This article is available at ARROW@TU Dublin: https://arrow.tudublin.ie/schfsehart/37 
4 Growth Inhibition of Common Food Spoilage Seaweed Extracts

\author{
Shilpi Gupta • Sabrina Cox • Gaurav Rajauria • \\ Amit Kumar Jaiswal • Nissreen Abu-Ghannam
}

Received: 18 August 2010 / Accepted: 22 December 2010

(C) Springer Science+Business Media, LLC 2010

Abstract The possibility of using extracts from brown seaweed, Himanthalia elongata, as a natural antimicrobial agent for food preservation is presented. The effect of different concentrations of seaweed extract on the growth kinetics of four common food spoilage (Pseudomonas aeruginosa and Enterococcus faecalis) and food pathogenic microorganisms (Listeria monocytogenes and Salmonella abony) was examined. Seaweed extract at a concentration of $6 \%$ inhibited the growth of all four of the studied organisms. Lower concentrations of seaweed extract prolonged the lag phase and reduced both the exponential growth rate and final population densities of the culture. Suitability of three kinetic models, Baranyi-Roberts, modified Gompertz and logistic, for describing the growth/survival of organisms in the presence of different concentrations of the extract, was evaluated. Root mean square error (RMSE) and correlation coefficient $\left(R^{2}\right)$ were used to evaluate the model performance. The $R^{2}$ value was greater than 0.95 for most of the cases indicating that the models could provide a good fitting to the experimental data. The RMSE and residual sum of squares were very low for all the three models, and no significant difference was observed in the goodness of fit between the three models as indicated by the $F$ test.

Keywords Seaweed $\cdot$ Non-thermal methods $\cdot$ Food preservation · Baranyi-Roberts · Modified Gompertz Logistic

S. Gupta $\cdot$ S. Cox $\cdot$ G. Rajauria $\cdot$ A. K. Jaiswal $\cdot$

\title{
Nomenclature
}

$A \quad$ The lower asymptotic line of the growth curve as $t$ decreases to zero

$B \quad$ The relative maximum specific growth rate (per hour) at time $M$

$C \quad$ The difference between the upper asymptotic line of the growth curve (maximum population level

$\left.N_{\max }\right)$ minus the lower asymptotic line $\left(N_{\max }-N_{0}\right)$ (log colony-forming unit (CFU) per millilitre)

$M \quad$ The time at which the specific growth rate is maximum (hours)

$N_{0} \quad$ Initial population level at time $t=0(\log$ CFU per millilitre)

$N_{t} \quad$ The cell number at any time $t(\log$ CFU per $\quad 58$ millilitre)

$N_{\max } \quad$ Maximum population level

$R^{2} \quad$ The coefficient of determination 63

RSS Residual sum of squares

RMSE Root mean square error

\section{Greek Letters}

$\gamma \quad \log _{10}$ maximum population density for Baranyi-

$\mu \quad$ Exponential specific growth rate for Baranyi-Roberts model (per hour)

$\mu_{\max }$ Maximum specific growth rate (per hour)

Preservatives are required to maintain the quality, extend shelf life and ensure safety of fresh and processed food products. Although chemical preservatives form an essential part in food preservation, legislation has restricted their 
use in different foods (Brul and Coote 1999). At the same time, consumer preferences are moving towards foods that contain lower levels of chemical preservatives, exhibit characteristics of fresh or natural products and are microbiologically safe as well.

Non-thermal methods such as the addition of naturally occurring compounds having antibacterial activity (Hayes et al. 2010), high pressure carbon dioxide (Garcia-Gonzalez et al. 2009), high intensity pulsed electric field (MosquedaMelgar et al. 2008), irradiation (Alighourchi et al. 2008) or ultrasound (Schenk et al. 2008; Salleh-Mack and Roberts 2007) are increasingly gaining attention for preservation of minimally processed foods. In recent years, the use of naturally occurring antimicrobial agents to inhibit pathogen growth and prevent food spoilage has received special attention (Hayes et al. 2010). Useful antimicrobial phytochemicals can be divided into several categories such as phenolics and polyphenols; quinines; flavones, flavonoids and flavonols; tannins; alkaloids and lectins; coumarins and polypeptides. Nowadays, minimal preservation processes based on the combined factors technology are also gaining importance for food preservation. Char et al. (2010) studied the response of Listeria innocua to combined treatments involving moderate temperatures and the addition of different levels of citral to obtain a minimally processed orange juice.

Seaweeds are considered a source of bioactive compounds as they are able to produce a great variety of secondary metabolites characterised by a broad spectrum of biological activities. Although seaweeds grow in a harsh environment, they seldom suffer any serious photodynamic damage during metabolism. This fact implies that seaweed cells have some protective compounds and mechanisms (Matsukawa et al. 1997). Since seaweeds are a good source of antimicrobial compounds, $\omega 3$ fatty acids, antioxidants and other bioactive compounds, there is an interest to utilize these products as nutraceuticals and in functional foods (Yuan 2008). Compounds, such as polyphenols, flavonoids and polysaccharides, having antioxidant and antimicrobial activities have been detected in brown, red and green algae (Cox et al. 2009; Zaragoza et al. 2008). Ara et al. (2002) reported brown algae to be active against a number of Gram-positive and Gram-negative organisms. Nagayama et al. (2002) reported that phlorotannins, brownalgal phenolic compounds, such as eckol and eckol-related compounds, from Ecklonia kurome, have strong bactericidal activity. A series of polyphenolic compounds such as catechins, flavonols and flavonol glycosides have been identified from methanol extracts of red and brown algae (Hosokawa et al. 2006) and found to have antioxidant and antimicrobial activity. Horie et al. (2008) isolated sargaquinoic acid derivatives from the brown alga Sargassum sagamianum having antibacterial properties.
Traditional microbial enumeration techniques are timeconsuming, and therefore, mathematical microbial models are used to assess the potential for growth of microorganisms in foods during processing and storage (Bovil et al. 2001). Empirical sigmoidal type models such as the modified Gompertz and logistic models or the semimechanistic model of Baranyi-Roberts have been used for fitting bacterial growth (Xiong et al. 1999). However, data on the use of actual plant extract for inhibiting microbial growth and modelling the resulting kinetics are scarce. Most of the studies done till date use either thermal treatments or purified compounds having antimicrobial activity for studying growth inhibition.

This study was conducted to determine the effect of different concentrations of brown seaweed (Himanthalia elongata) extract against Listeria monocytogenes, Salmonella abony, Enterococcus faecalis and Pseudomonas aeruginosa. There are some reports available wherein the antimicrobial effect of seaweed extract has been studied on different organisms (Taskin et al. 2010; Cox et al. 2009; Ely et al. 2004; Nagayama et al. 2002), but no studies are available where the growth inhibition has been modelled. Hence, the present study investigates the utilization of methanolic extract from brown seaweed as a natural antimicrobial agent for food preservation by examining its effects on the growth kinetics of four common food spoilage and food pathogenic microorganisms. In order to describe growth inhibition in the presence of seaweed extract, performance of three commonly used primary models, namely the Baranyi-Roberts, modified Gompertz and logistic models, was evaluated.

\section{Materials and Methods}

Seaweed Material

Brown seaweed H. elongata (Pheophyta) was purchased from Quality Sea Veg., Co. Donegal, Ireland. Samples were received in September 2009 and washed thoroughly with freshwater to remove epiphytes and salt.

Preparation of Seaweed Extracts

The extraction of seaweed was carried out with $60 \%$ methanol under nitrogen atmosphere at $40{ }^{\circ} \mathrm{C}$ and $100 \mathrm{rpm}$ in a shaker incubator (Innova 42, Mason Technology, Ireland). Samples were filtered and centrifuged at $10,000 \mathrm{rpm}(8,720 \times \mathrm{g})$ for $15 \mathrm{~min}$ (Sigma $2 \mathrm{~K} 15$, Mason Technology, Ireland). Resulting extracts were evaporated to dryness using vacuum polyevaporator (Buchi Syncore Polyvap, Mason Technology, Ireland) at $60{ }^{\circ} \mathrm{C}$. A pressure gradient programme was designed for evaporation of the 
Food Bioprocess Technol

187 solvents with vacuum conditions of 33,700 and 7,200 $\mathrm{Pa}$

188 for methanol and water, respectively.

189 Antimicrobial Activity

190

\section{Microbial Culture}

Two species of common food pathogenic and food spoilage bacteria selected for this study were L. monocytogenes (ATCC 19115), S. abony (NCTC 6017), E. faecalis (ATCC 7080) and P. aeruginosa (ATCC 27853), respectively (Medical Supply Company, Dublin, Ireland). All cultures were maintained at $-70{ }^{\circ} \mathrm{C}$ in $20 \%$ glycerol stocks and grown in Tryptic Soy Broth (TSB; Scharlau Chemie, Barcelona, Spain) at $37^{\circ} \mathrm{C}$, except for $P$. aeruginosa which was incubated at $30{ }^{\circ} \mathrm{C}$, to obtain sub-cultures. A final cell concentration of $1 \times 10^{6}$ colony-forming units $(\mathrm{CFU}) / \mathrm{ml}$ was used for the experiments.

\section{Relation Between Turbidity and Viable Count}

Before the kinetics study, a relationship between optical density at $600 \mathrm{~nm}$ and viable count was determined for all of the bacteria studied. A volume of $200 \mu \mathrm{l}$ of bacterial suspension containing $6 \log \mathrm{CFU} / \mathrm{ml}$ was dispensed into 50 wells of the 96-well microtitre plate (Sarstedt Ltd., UK). Every hour, the optical density (OD) of the microtitre plate was read. At the same time, an aliquot of $100 \mu \mathrm{l}$ from one well was transferred into $900 \mu \mathrm{l}$ of maximum recovery diluent (Scharlau Chemie, Barcelona, Spain) to determine the viable cell count. Spreading was carried out on Tryptic soy agar (Scharlau Chemie, Barcelona, Spain) plates by taking $100 \mu \mathrm{l}$ of relevant dilution. Plates were incubated at $37^{\circ} \mathrm{C}$, with the exception of $P$. aeruginosa $\left(30^{\circ} \mathrm{C}\right)$, for $24 \mathrm{~h}$ before determining the $\mathrm{CFU}$ per millilitre. A standard curve $\left(\mathrm{OD}_{600 \mathrm{~nm}}\right.$ vs. $\log \mathrm{CFU}$ per millilitre) was drawn from the results obtained. This curve was later used for conversion of the OD values to $\log$ CFU per millilitre for respective bacteria in the presence of seaweed extract.

\section{Antimicrobial Activity Assay}

The influence of varying concentrations of extract on efficacy was assessed against the four organisms using 96-well microtitre plates. Extract $(300 \mathrm{mg})$ obtained from $5 \mathrm{~g}$ fresh seaweed was dissolved in TSB $(2.5 \mathrm{ml})$, and $200 \mu \mathrm{l}$ was added to the first row of each plate. All other wells were filled with $100 \mu \mathrm{l}$ of TSB, and $100 \mu \mathrm{l}$ from the first well was serial diluted into 2-fold along each column. Finally, $100 \mu \mathrm{l}$ of bacterial suspension containing $6 \log \mathrm{CFU} / \mathrm{ml}$ was added to the wells. The last row was used for bacterium and media controls. Sample blanks were also prepared for all of the extracts.
The plate was incubated in the microtitre reader for $24 \mathrm{~h}$ at respective temperature for each organism. Microbial growth was recorded every $2 \mathrm{~h}$ on a Powerwave microplate spectrophotometer (Powerwave, Biotek) driven by Gen5 reader control and data analysis software. Turbidity was measured as absorbance at $600 \mathrm{~nm}$, with $20 \mathrm{~s}$ agitation before each OD measurement. The OD values were converted to log CFU per millilitre by the standard curve as described in "Relation Between Turbidity and Viable Count" section.

Growth Curve

To describe the inhibition of bacterial growth in the presence of seaweed extract, three primary growth models, namely modified Gompertz, logistic and Baranyi-Roberts model, were fitted to the data, and their performance was comparatively evaluated. Growth curves were plotted to evaluate the antibacterial activities of the seaweed extract.

\section{Baranyi-Roberts Model}

A programme implemented in Microsoft Excel (DM-Fit; Institute of Food Research, Norwich, UK) was used to fit the equation of Baranyi and Roberts (1994) to the growth data. To evaluate the effect of different extract concentrations main kinetic parameters such as exponential specific growth rate $(\mu), \log _{10}$ maximum population density $(\gamma)$, lag time $(\lambda)$ and the coefficient of determination $\left(R^{2}\right)$ were calculated.

\section{Modified Gompertz Model}

The modified Gompertz model (Gibson et al. 1987) is given by Eq. 1,

$N_{t}=A+C \times \exp [-\exp \{-B \times(t-M)\}]$

where $N_{t}$ is the cell number (log CFU per millilitre) at any time $t, A$ is the lower asymptotic line of the growth curve as $t$ decreases to zero (that is $N_{0}$ : initial population level at time $t=0(\log$ CFU per millilitre $), C$ is the difference between the upper asymptotic line of the growth curve (maximum population level, $N_{\max }$ ) minus the lower asymptotic line (for example, $N_{\max }-N_{0}$ (log CFU per millilitre)), $B$ is the relative maximum specific growth rate (per hour) at time $M$ and $M$ is the time at which the specific growth rate is maximum. Equations 2, 3 and 4 can then be used for the calculation of maximum specific growth rate ( $\mu_{\max }$ (per hour)), lag phase duration ( $\lambda$, hours) and maximum cell population $\left(N_{\max }\right)$, respectively:

$\mu_{\max }=\frac{B \times C}{e}$ 
where $e=2.7182$

$\lambda=M-\frac{1}{B}$

288

$N_{\text {max }}=A+C$

\section{Logistic Model}

The logistic model used for defining bacterial growth as a function of time at constant environmental conditions, such as temperature, $\mathrm{pH}$, water activity etc. is given by Eq. 5 (Gibson et al. 1987):

$N_{t}=A+\frac{C}{1+\exp [-B \times(t-M)]}$

where $N_{t}, A, B, M$ and $C$ have the same meaning as given for the modified Gompertz equation. The $\mu_{\max }$ and $\lambda$ parameters can be calculated by Eqs. 6 and 7, respectively, as follows:

$\mu_{\max }=\frac{B \times C}{4}$

$\lambda=M-\frac{2}{B}$

\section{Model Comparison}

Root Mean Square Error The smaller the root mean square error (RMSE) values, the better the fit of the model to the data.

$\mathrm{RMSE}=\sqrt{\frac{\sum(\text { predicted }- \text { observed })^{2}}{n-p}}$

where $n$ is the number of observations and $p$ the number of parameters to be estimated.

\section{Curve Fitting}

A plot of microbial count versus time for each extract concentration was used to derive the starting values for the parameters, $N_{0}$ and $N_{\max }$, for all three models evaluated. The lag time was obtained from the raw data by noting the time when exponential growth started. The experimental data were fitted to equations described above by nonlinear regression with a Marquardt algorithm using the software Statgraphics Centurion XV (StatPoint Technologies, Inc., Warrenton, VA, USA). The aim of the fitting procedure was to find each model's parameters that best described the data by minimizing the sum of the squares of the differences between the model simulated and experimental values.

Statistical Analysis

All experiments were performed in duplicate and replicated at least three times. All statistical analyses were carried out using STATGRAPHICS Centurion XV. Statistical differences between extract activities were determined using ANOVA followed by least significant difference testing. Differences were considered statistically significant when $p<0.05$.

\section{Results and Discussion}

Antimicrobial Effect of Different Concentrations of $H$. elongata Extracts

In our previous study (Cox et al. 2009), we had reported the antioxidant capacity of six species of Irish seaweeds and found the methanolic extracts from $H$. elongata to be the richest in terms of antioxidant properties. The selection of the pathogenic microbes (L. monocytogenes and S. abony) was made after discussions with the Food Safety Authority of Ireland as these were found to be the most challenging organisms for the safety of food products in Ireland. The other two (E. faecalis and P. aeruginosa) are the most widespread food spoilage microorganisms. Since the yield of the extract obtained was only $60 \mathrm{mg} / \mathrm{g}$ seaweed, growth inhibition was checked by measuring the OD by a microtitre plate-based assay rather than by the conventional spread plate method. As expected, control samples showed a rapid and prolific growth, as the populations were 9.6, 10, 14.1 and $17.2 \log \mathrm{CFU} / \mathrm{ml}$ after $24 \mathrm{~h}$ for $S$. abony, $L$. monocytogenes, $P$. aeruginosa and E. faecalis, respectively (Fig. 1). The incorporation of seaweed extract resulted in variable levels of inhibition in the growth of the different organisms. Resistance to extract was not correlated with taxonomy, since E. faecalis (Gram positive) and $P$. aeruginosa (Gram negative) were the most sensitive to all of the different concentrations of the extract followed by $S$. abony and L. monocytogenes. Figure 1 shows the influence of the different concentrations of crude extracts obtained from $H$. elongata against the four studied organisms. The extract had a strong antagonizing effect on the food spoilage and pathogens studied, showing a remarkable dose-response relationship with an increase of the lag phase duration and decrease of the exponential growth rate. In addition, a reduction in the maximum number attained or a complete suppression of growth was observed. The addition of $H$. elongata extracts resulted in complete
330 331 332 333 334 335 336 337 338 339 340 341 
Food Bioprocess Technol

Fig. 1 Growth kinetics of food spoilage and pathogenic bacteria in presence of different concentrations of seaweed extract: a $L$. monocytogenes, b $P$. aeruginosa, c E. faecalis and $\mathbf{d} S$. abony. Different concentrations of extract used: diamond $6 \%$, black triangle $3 \%$, circle $1.5 \%$, square $0.75 \%$, asterisk $0.375 \%$ and white triangle $0 \%$
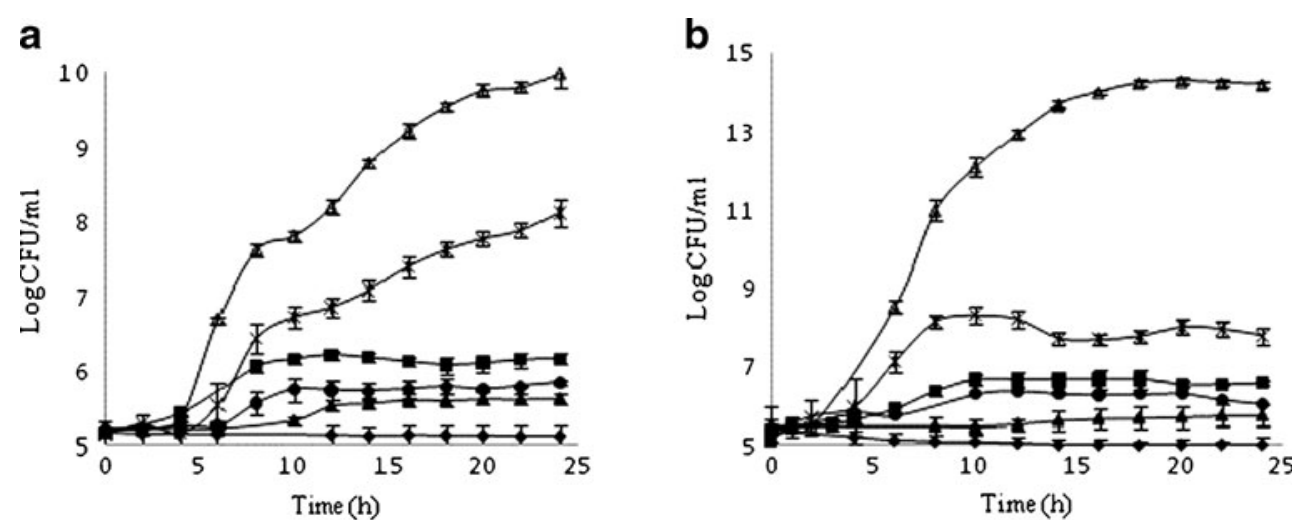

C

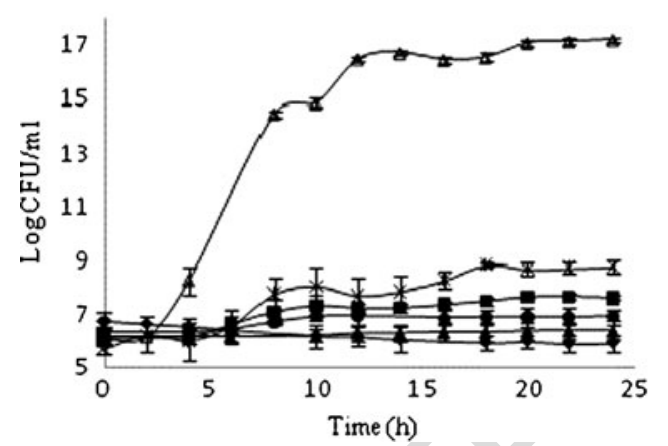

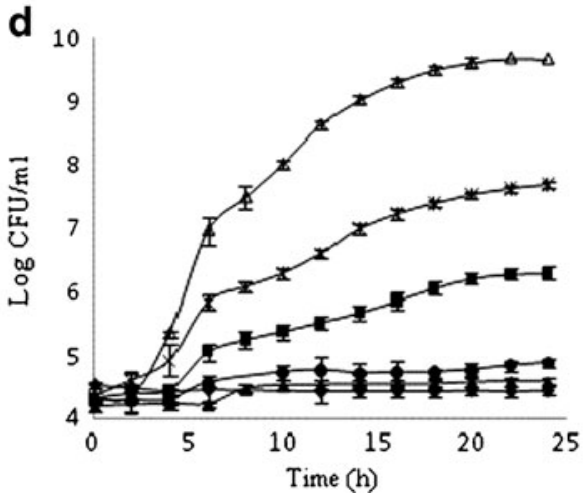

growth inhibition of all the studied organisms at the highest extract concentration (6\%) used (Fig. 1). The bactericidal activity can be attributed due to the presence of phenolic compounds such as bromophenols and phlorotannins, produced by brown algae (Nagayama et al. 2002). Phenolic compounds from other plant sources have also been reported to inhibit various foodborne pathogens (Plaza et al. 2010; Kim et al. 2005; Prashanth et al. 2001). Polyphenols, such as tannins and flavonoids, are important antibacterial substances. Halogen-containing terpenoids, acetylenes and phenols have also been identified in several seaweed species as biologically active compounds having antibacterial and anti-tumoural activities (Cardozo et al. 2007; Vairappan et al. 2001; Carvalho and Roque 2000). Plaza et al. (2010) identified volatile compounds like fatty acids, alkanes, phenols and compounds such as phytol (2hexadecen-1-ol, 3,7,11,15-tretramethyl) and neophytadiene in the ethanol extracts from Synechocystis sp. and $H$. elongata. These compounds have been already proposed to have antimicrobial activity (Alagić et al. 2006).

The cell density in the presence of $6 \%$ extracts upon completion of the assay $(24 \mathrm{~h})$ was lower for all four bacteria than the initial bacterial density. Similar effect was seen in earlier studies on the effect of seaweed extracts on growth of marine and fish pathogenic extracts (Dubber and Harder 2008) where it had been anticipated the reason for this frequently observed result could be associated with the complete disappearance of the bacterial DNA upon incu- bation with algal extract components. Therefore, the extracts presumably evoked not only a bacteriostatic but also bacteriolytic mode of action. Studies by Ceylan et al. (1998) revealed that addition of 1\% spice (garlic, clove and cinnamon) to salami mixed with starter culture and Escherichia coli $\mathrm{O} 157: \mathrm{H} 7$ resulted in slight reduction of the pathogen; however, the addition of $7.5 \%$ garlic and clove killed $99 \%$ of the pathogen. Similar results were obtained in the present study as well wherein addition of $6 \%$ extracts resulted in growth inhibition and extract concentrations lesser than that caused a reduction in the cell numbers.

As the extract concentration was serially diluted, the inactivation effect was reduced. Although the addition of extracts at a concentration of $3 \%$ did not result in a complete inactivation of bacteria, the growth kinetics was highly altered. An increase in the cell number, after $24 \mathrm{~h}$ of incubation with $3 \%$ extract, for each of the four bacteria was in the range of $0.21-0.43 \log \mathrm{CFU} / \mathrm{ml}$. A lag phase much longer than the control was observed, and the specific growth rate was significantly reduced for all the organisms. At the same time, a reduction of $98 \%$ (E. faecalis), $97 \%$ ( $P$. aeruginosa), 93\% (S. abony) and 91\% (L. monocytogenes) in the stationary level growth was observed as compared to the control. There was a significant difference $(p<0.05)$ in the stationary phase growth $(24 \mathrm{~h})$ of $P$. aeruginosa, $E$. faecalis, L. monocytogenes and $S$. abony upon the addition of $3 \%, 1.5 \%$ and $0.75 \%$ extract. The increase in the cell 
number upon the addition of $1.5 \%$ extract, after $24 \mathrm{~h}$ incubation, was in the range of $0.6-0.8 \log \mathrm{CFU} / \mathrm{ml}$. Thus, it can be said that addition of these concentrations of extracts resulted in an extended lag phase. Despite the fact that reducing the extract concentration to $0.75 \%$ resulted in a lag phase similar to that of the control, the specific growth rate was highly suppressed. Hence, an increase of 1.5-, 1.6-, 2.2and 2.3-fold in the stationary phase growth of $S$. abony, $L$. monocytogenes, $P$. aeruginosa and E. faecalis, respectively, was seen in the control ( $0 \%$ extract) as compared to samples containing $0.75 \%$ extract. Thus, the bacteria started to grow at almost similar times, but the presence of the extract suppressed the maximum cell number attained. This was further evident from a slight increase of $1-1.9 \log \mathrm{CFU} / \mathrm{ml}$ for each of the four bacteria after $24 \mathrm{~h}$ growth. Reducing the extract concentration further to $0.35 \%$ and $0.18 \%$ resulted in growth patterns very similar to the control in case of $L$. monocytogenes and S. abony.

The present study utilized methanol as a solvent for extraction of compounds responsible for the observed effect. Studies are also available wherein different solvents have been utilized for the extraction of biologically active

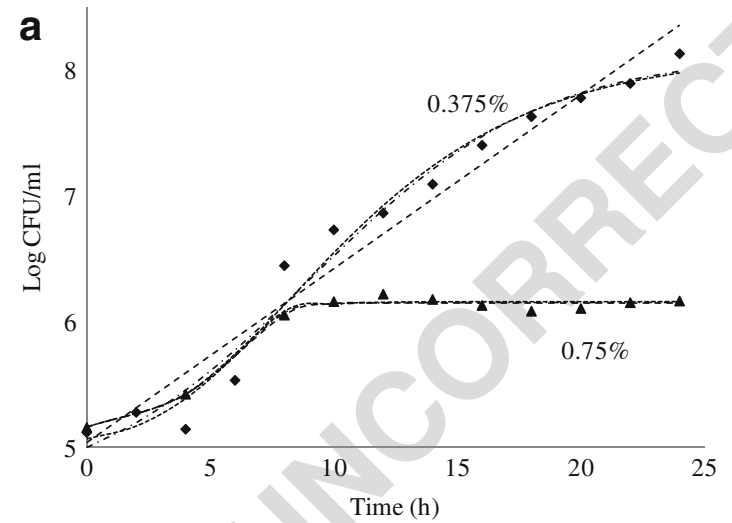

c

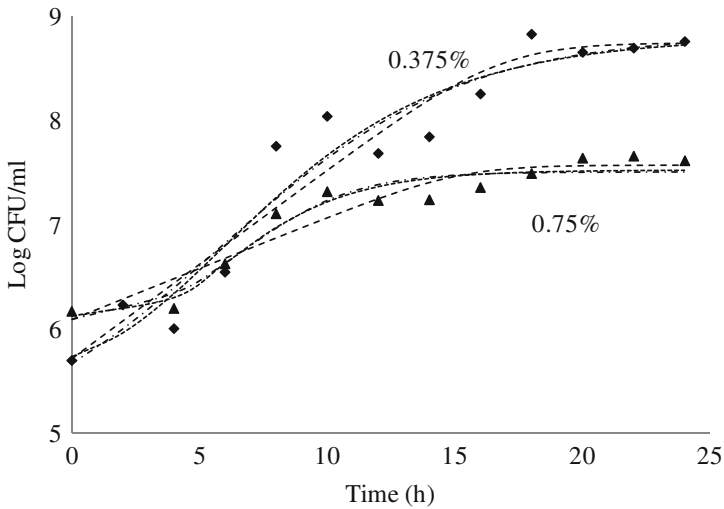

Fig. 2 Fitting of the three models to the inactivation of the four organisms by extract at a concentration of $0.75 \%$ and $0.375 \%$. a $L$. monocytogenes, b $P$. aeruginosa, c E. faecalis and d $S$. abony. Different concentrations of extract used: triangle $0.75 \%$ and diamond compounds from seaweeds. Earlier reports on the effectiveness of extraction methods evidenced that methanol extraction yielded higher antimicrobial activity than other solvents such as $n$-hexane and ethyl acetate (Sastry and Rao 1994; Paul and Puglisi 2004). It is well documented that using organic solvents always provides a higher efficiency in extracting compounds for antimicrobial activities as compared to water-based methods (Masuda et al. 1997; Lima-Filho et al. 2002).

A significant finding of the present study was the potency of the extract against Gram-negative bacteria $(P$. aeruginosa). Gram-negative bacteria are more resistant pathogens compared to the Gram-positive bacteria. They have an additional lipopolysaccharide layer on the outer surface which prevents certain drugs and antibiotics from penetrating the cell thus accounting for the high resistance of these bacteria to antibiotics (Dowling 2004). Therefore, the present study brings out a new insight towards the development of antimicrobial agents against Gram-negative bacteria from seaweeds. In recent years, the use of nonthermal techniques for preservation of food has been gaining importance. The use of ozone, irradiation or
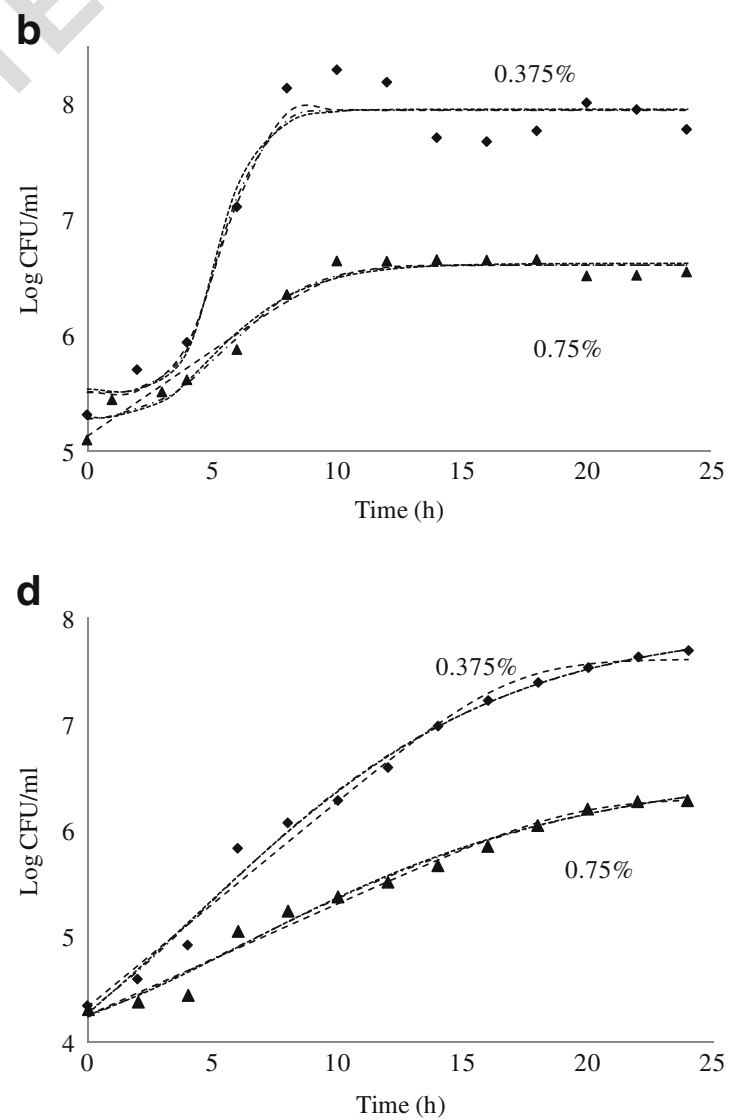

0.375\%. Different models: dotted line modified Gompertz model equation, dashed line Baranyi-Roberts model equation and dashdotted line logistic model equation. Points represent experimental data 
Food Bioprocess Technol

463 ultrafiltration is better than thermal sterilization but can 464 have a detrimental impact on the bioactive compounds 465 present in foods if used at higher levels (Tiwari et al. 2009; 466 Alighourchi et al. 2008; Zárate-Rodríguez et al. 2000). In 467 this regard, the use of natural antimicrobials in foods to 468 prevent spoilage might also provide the additional benefit 469 of preserving the bioactive properties of foods. Thus, the 470 addition of extracts from seaweeds can not only impart 471 microbiological safety to food products as they are rich in 472 bioactives (Cox et al. 2009) but can also provide foods with 473 antioxidants in order to prevent oxidative spoilage.

\section{Comparison of Kinetic Models}

Generally, the models that can be used for describing the kinetics of survival curves are either empirical or based on biological assumptions. Three primary growth models (modified Gompertz (empirical), logistic (empirical) and Baranyi-Roberts model (semi-mechanistic model)) were used to analyse the delay or inhibition of growth against the four different organisms. In most of the cases, the $R^{2}$ values for all the models were greater than 0.9 (except when extract at a concentration of $1.5 \%$ was added to $P .483$ aeruginosa), indicating a good fit to the experimental data. 484 Examples of the fit of the three models to the inactivation 485 of the four organisms at an extract concentration of $0.75 \% \quad 486$ and $0.375 \%$ are depicted in Fig. 2. All the parameters 487 obtained for the three mathematical models were directly 488 related to the extract concentration. Analyses of variance 489 indicated that the maximum specific growth rate, $\mu_{\max }$, was 490 significantly reduced $(p<0.05)$ with increasing extract 491 concentration suggesting that the cells became more 492 sensitive (Table 1). The estimated values for the lag phase 493 for all the three models tended to increase as the extract 494 concentration increased. In individual model analysis, it 495 was found that all the three models were capable of fitting 496 the experimental data very reasonably and produced almost 497 similar curves; however, no model could produce consis- 498 tently best fit to all the growth curves analysed. RMSE 499 (Table 2) was used as a statistical measure for comparison 500 of the experimental and model simulated values. There was 501 no significant difference between the RMSE $(p>0.05)$ for 502 the three models. One way to discriminate the goodness of 503 fit among different models is to compare them statistically 504

Table 1 Estimations of the kinetic parameters using the logistic, modified Gompertz and the Baranyi-Roberts models

\begin{tabular}{|c|c|c|c|c|c|c|c|c|c|}
\hline & \multirow[b]{2}{*}{ Conc. $(\%)$} & \multicolumn{2}{|l|}{ Logistic } & \multicolumn{3}{|c|}{ Baranyi-Roberts } & \multicolumn{3}{|c|}{ Gompertz } \\
\hline & & $\mu$ & Lag & $\mu$ & Lag & $A$ & $\mu$ & Lag & $A$ \\
\hline \multirow[t]{6}{*}{ L. monocytogenes } & 6 & -0.0062 & $->$ & -0.0032 & - & - & -0.007 & - & 4.94 \\
\hline & 3 & 0.101 & 8.75 & 0.104 & 8.83 & 5.62 & 0.109 & 8.83 & 5.63 \\
\hline & 1.5 & 0.195 & 6.24 & 0.18 & 6.106 & 5.77 & 0.179 & 6.02 & 5.77 \\
\hline & 0.75 & 0.212 & 2.8 & 0.173 & 2.56 & 6.15 & 0.256 & 2.99 & 6.15 \\
\hline & 0.375 & 0.191 & - & 0.137 & - & - & 0.209 & 2.77 & 8.13 \\
\hline & 0 & 0.336 & - & 0.287 & - & 9.89 & 0.364 & 1.74 & 10.12 \\
\hline \multirow[t]{6}{*}{ S. abony } & 6 & -0.163 & 1.73 & -0.026 & - & 4.43 & -0.177 & 1.75 & 4.43 \\
\hline & 3 & 0.169 & 6.4 & 0.154 & 6.24 & 4.55 & 0.144 & 6.02 & 4.55 \\
\hline & 1.5 & 0.223 & 0.47 & 0.191 & 4.49 & 4.76 & 0.148 & 4.05 & 4.77 \\
\hline & 0.75 & 0.116 & - & 0.105 & - & 6.31 & 0.12 & - & 6.57 \\
\hline & 0.375 & 0.22 & - & 0.193 & - & 7.61 & 0.226 & - & 7.95 \\
\hline & 0 & 0.471 & - & 0.399 & - & 9.56 & 0.515 & 1.1 & 9.71 \\
\hline \multirow[t]{6}{*}{ P. aeruginosa } & 6 & -0.005 & - & -0.0415 & - & 5.03 & -0.053 & - & 5.02 \\
\hline & 3 & 0.035 & 10.3 & 0.0275 & 9.59 & 5.74 & 0.035 & 10.43 & 5.74 \\
\hline & 1.5 & 0.129 & 2.5 & 0.102 & - & 6.25 & 0.141 & 0.74 & 6.25 \\
\hline & 0.75 & 0.213 & - & 0.148 & - & 6.61 & 0.218 & 2.59 & 6.62 \\
\hline & 0.375 & 0.764 & 3.74 & 0.669 & 3.54 & 7.94 & 0.808 & 3.65 & 7.95 \\
\hline & 0 & 0.991 & 2.06 & 0.8127 & 1.49 & 14.118 & 1.09 & 3.1 & 14.25 \\
\hline \multirow[t]{6}{*}{ E. faecalis } & 6 & -0.055 & - & -0.049 & - & 5.92 & -0.057 & - & 5.85 \\
\hline & 3 & 0.017 & 6.4 & 0.0104 & - & - & 0.019 & 7.38 & 6.37 \\
\hline & 1.5 & 0.167 & 5.55 & 0.147 & 5.33 & 6.88 & 0.173 & 5.47 & 6.88 \\
\hline & 0.75 & 0.171 & 2.51 & 0.098 & - & 7.56 & 0.183 & 3.22 & 7.52 \\
\hline & 0.375 & 0.216 & - & 0.18 & - & 8.73 & 0.235 & 0.985 & 8.79 \\
\hline & 0 & 1.54 & 2.19 & 1.29 & 1.87 & 16.78 & 1.63 & 2.58 & 16.9 \\
\hline
\end{tabular}


Table 2 Values of the statistical indices, RMSE and RSS, for the three models against four different bacteria at six different extract concentrations
$A$ logistic, $B$ Baranyi-Roberts, $C$ modified Gompertz equation

\begin{tabular}{|c|c|c|c|c|c|c|c|c|}
\hline & \multirow[b]{2}{*}{ Conc. $(\%)$} & \multicolumn{3}{|c|}{ RMSE } & \multicolumn{3}{|l|}{ RSS } & \multirow{2}{*}{$\begin{array}{l}\mathrm{t} 2.2 \\
\mathrm{t} 2.3\end{array}$} \\
\hline & & A & $\mathrm{B}$ & $\mathrm{C}$ & A & $\mathrm{B}$ & $\mathrm{C}$ & \\
\hline \multirow[t]{6}{*}{ L. monocytogenes } & 6 & 0.01 & 0.0 & 0.01 & 0.0 & 0.0 & 0.0 & $\mathrm{t} 2.4$ \\
\hline & 3 & 0.015 & 0.018 & 0.012 & 0.0018 & 0.0027 & 0.0012 & $\mathrm{t} 2.5$ \\
\hline & 1.5 & 0.035 & 0.036 & 0.035 & 0.0113 & 0.012 & 0.0113 & $\mathrm{t} 2.6$ \\
\hline & 0.75 & 0.044 & 0.043 & 0.046 & 0.014 & 0.013 & 0.0146 & $\mathrm{t} 2.7$ \\
\hline & 0.375 & 0.197 & 0.27 & 0.181 & 0.351 & 0.659 & 0.295 & $\mathrm{t} 2.8$ \\
\hline & 0 & 0.273 & 0.310 & 0.251 & 0.673 & 0.865 & 0.567 & $\mathrm{t} 2.9$ \\
\hline \multirow[t]{6}{*}{ S. abony } & 6 & 0.01 & 0.010 & 0.01 & 0.0 & 0.0 & 0.0 & $\mathrm{t} 2.10$ \\
\hline & 3 & 0.023 & 0.023 & 0.021 & 0.004 & 0.004 & 0.004 & $\mathrm{t} 2.11$ \\
\hline & 1.5 & 0.057 & 0.057 & 0.056 & 0.026 & 0.026 & 0.025 & $\mathrm{t} 2.12$ \\
\hline & 0.75 & 0.109 & 0.116 & 0.108 & 0.108 & 0.121 & 0.104 & $\mathrm{t} 2.13$ \\
\hline & 0.375 & 0.126 & 0.156 & 0.13 & 0.147 & 0.219 & 0.153 & $\mathrm{t} 2.14$ \\
\hline & 0 & 0.238 & 0.306 & 0.206 & 0.51 & 0.842 & 0.388 & $\mathrm{t} 2.15$ \\
\hline \multirow[t]{6}{*}{ P. aeruginosa } & 6 & 0.01 & 0.026 & 0.01 & 0.0 & 0.01 & 0.0 & $\mathrm{t} 2.16$ \\
\hline & 3 & 0.019 & 0.021 & 0.015 & 0.0024 & 0.003 & 0.001 & $\mathrm{t} 2.17$ \\
\hline & 1.5 & 0.146 & 0.133 & 0.149 & 0.148 & 0.124 & 0.155 & $\mathrm{t} 2.18$ \\
\hline & 0.75 & 0.106 & 0.106 & 0.121 & 0.112 & 0.112 & 0.147 & $\mathrm{t} 2.19$ \\
\hline & 0.375 & 0.332 & 0.233 & 0.257 & 0.994 & 0.488 & 0.595 & $\mathrm{t} 2.20$ \\
\hline & 0 & 0.235 & 0.337 & 0.15 & 0.44 & 0.909 & 0.181 & $\mathrm{t} 2.21$ \\
\hline \multirow[t]{6}{*}{ E. faecalis } & 6 & 0.027 & 0.031 & 0.027 & 0.004 & 0.006 & 0.004 & $\mathrm{t} 2.22$ \\
\hline & 3 & 0.019 & 0.026 & 0.017 & 0.002 & 0.005 & 0.002 & $\mathrm{t} 2.23$ \\
\hline & 1.5 & 0.021 & 0.017 & 0.027 & 0.003 & 0.002 & 0.005 & $\mathrm{t} 2.24$ \\
\hline & 0.75 & 0.155 & 0.185 & 0.139 & 0.192 & 0.272 & 0.156 & $\mathrm{t} 2.25$ \\
\hline & 0.375 & 0.337 & 0.357 & 0.332 & 1.026 & 1.147 & 0.994 & $\mathrm{t} 2.26$ \\
\hline & 0 & 0.455 & 0.559 & 0.374 & 1.65 & 2.51 & 1.12 & $\mathrm{t} 2.27$ \\
\hline
\end{tabular}

concentration on the bacterial growth. The most prominent effect of the extract was an increase in the lag phase duration. The increase in lag phase due to the addition of extract at a concentration of 3\% was more than 3 -fold for $L$. monocytogenes and $P$. aeruginosa as compared to the control. A delay in, or inhibition of, microbial growth is particularly useful in terms of food safety. The extension of the lag phase is probably the most widely used parameter to describe the inhibitory effects of antimicrobial compounds, and a slight delay in the lag phase may have an important

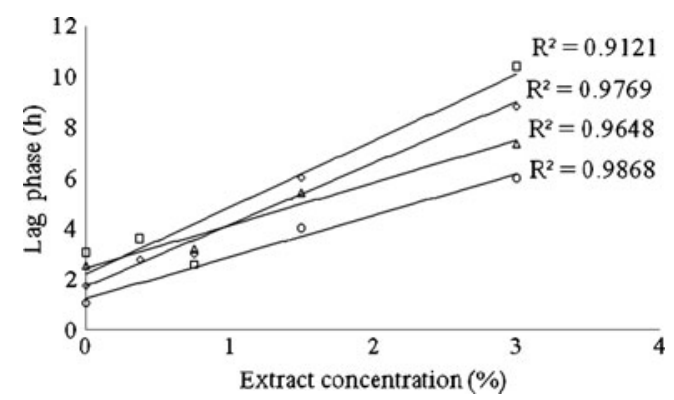

Fig. 3 Relation between lag phase and concentration of extract against the four different organisms (diamond-L. monocytogenes, circle - S. abony, square - P. aeruginosa and triangle - E. faecalis) 
influence on the shelf life of food products. Thus, the prolonging of lag phase could be used as an appropriate index for evaluation of the activity of the antimicrobial compounds. In the present study, a linear positive correlation ( $R^{2}$ ranging between 0.912 and 0.986 ) was obtained between the lag phase and the concentration of seaweed extract for the different organisms (Fig. 3). The seaweed extracts were potent even at an extract concentration as low as $0.75 \%$ resulting in $42 \%$ and $20 \%$ increase in the lag phase of L. monocytogenes and E. faecalis, respectively, as compared to the control. Extract concentration of $3 \%$ increased the lag phase in a range of $65 \%$ to $81 \%$ for all of the organisms. In an early report on microbial growth modelling of fresh filled pasta stored at different temperatures by Giannuzzi (1998), it was observed that the ratio of specific growth rate to generation time was nearly constant which suggests a linear relationship between lag phase and the reciprocal of the maximum specific growth rate. Similar observations were confirmed in the present study during the inactivation of the four organisms at different extract concentrations.

The concentration of extract also had a strong effect on the maximum specific growth rate. A reduction of $99 \%$ and $96.8 \%$ was observed in the maximum specific growth rate, as compared to control at $3 \%$ extract concentration $(E$. faecalis and $P$. aeruginosa, respectively).

It has been reported in the literature that flavonoids, polysaccharides, sesquiterpenes and phlorotannins can be obtained from seaweeds. These active ingredients produce varied pharmacological effects such as anti-angiogenic, anti-inflammation, disinfection and anti-tumour. The application of the extracts of $H$. elongata in food industry may contribute to such pharmacological activities as food antioxidation, health care and in addition as food nutrient. Therefore, these extracts could be applied as natural additives with extensive market prospect.

\section{Conclusion}

H. elongata can be considered as a promising marine plant in the development of bioactive ingredients for functional foods, nutraceuticals and other applications. The extracts showed an evident antimicrobial effect against the microorganisms used in the present study in a dose-dependent manner. Complete growth inactivation of all of the studied organisms was observed at a concentration of $6 \%$. Addition of extracts at a concentration less than that resulted in an extension of the lag phase and significantly reduced maximum specific growth rate. A reduction of $91-98 \%$ in the stationary level growth as compared to the control was also observed. The findings suggest that seaweed extracts have a good potential as natural antibacterial substances in food preservation. It might be possible that high concentrations of these extracts may adversely affect the organoleptic properties of food; however, lower concentrations may be sufficient for food safety in situations where bacterial load is low.

Acknowledgement The authors would like to acknowledge funding from the Irish Government under the Technological Sector Research Scheme (Strand III) of the National Development Plan.

\section{References}

Alagić, S., Stančić, I., Palić, R., Stojanović, G., \& Lepojević, Ž. (2006). Chemical composition of the supercritical $\mathrm{CO}_{2}$ extracts of the Yaka, Prilep and Otlja tobaccos. J Essent Oil Res, 18(2), 185-188.

Alighourchi, H., Barzegar, M., \& Abbasi, S. (2008). Effect of gamma irradiation on the stability of anthocyanins and shelf-life of various pomegranate juices. Food Chem, 110(4), 1036-1040.

Ara, J., Sultana, V., Ehteshamul-Haque, S., Athar, M., \& Qasim, R. (2002). Antibacterial activity of marine macroalgae from Karachi coast. Bull Pol Acad Sci, 50, 199-206.

Baranyi, J., \& Roberts, T. A. (1994). A dynamic approach to predicting bacterial growth in food. Int $J$ Food Microbiol, 23 (3-4), 277-294.

Bovil, R. A., Bew, J., \& Baranyi, J. (2001). Measurements and predictions of growth for Listeria monocytogenes and Salmonella during fluctuating temperature. II. Rapidly changing temperatures. Int J Food Microbiol, 67(1-2), 131-137.

Brul, S., \& Coote, P. (1999). Preservative agents in foods-mode of action and microbial resistance mechanisms. Int J Food Microbiol, 50(1-2), 1-17.

Cardozo, K. H. M., Guaratini, T., Barros, M. P., Falcão, V. R., Tonon, A. P., Lopes, N. P., et al. (2007). Metabolites from algae with economical impact. Comp Biochem Physiol C, 146 (1-2), 60-78.

Carvalho, L. R., \& Roque, N. F. (2000). Halogenated and/or sulphated phenols from marine macroalgae. Quim Nova, 23(6), 757-765.

Ceylan, E., Kang, D., Daniel, Y. C. F. (1998). Spices may reduce Escherichia coli $\mathrm{O} 157: \mathrm{H} 7$ in meat. Available at http://genetics. miningco.com/library/blpressecoli.htm. Accessed on 5 Aug 2010.

Char, C. D., Guerrero, S. N., \& Alzamora, S. M. (2010). Mild thermal process combined with vanillin plus citral to help shorten the inactivation time for Listeria innocua in orange juice. Food Bioprocess Technol, 3(5), 752-761.

Cox, S., Abu-Ghannam, N., \& Gupta, S. (2009). An assessment of the antioxidant and antimicrobial activity of six species of edible Irish seaweeds. Int Food Res J, 17(1), 205-220.

Dowling, P. M. (2004). Antimicrobial therapy. In H. Bertone (Ed.), Equine clinical pharmacology (pp. 13-48). London: Saunders.

Dubber, D., \& Harder, T. (2008). Extracts of Ceramium rubrum, Mastocarpus stellatus and Laminaria digitata inhibit growth of marine and fish pathogenic bacteria at ecologically realistic concentrations. Aquaculture, 274(2-4), 196-200.

Ely, R., Supriya, T., \& Naik, C. G. (2004). Antimicrobial activity of marine organisms collected off the coast of South East India. $J$ Exp Mar Biol Ecol, 309(1), 121-127.

Garcia-Gonzalez, L., Geeraerd, A. H., Elst, K., Van Ginneken, L., Van Impe, J. F., \& Devlieghere, F. (2009). Influence of type of microorganism, food ingredients and food properties on highpressure carbon dioxide inactivation of microorganisms. Int $J$ Food Microbiol, 129(3), 253-263. 
649
Geeraerd, A., Herremans, C., Van Impe, J. (1997). Structural model requirements to describe microbial inactivation. In: Proceedings Science and Technology (International Institute of Refrigeration). Predictive microbiology applied to chilled food preservation ( $\mathrm{pp}$ 280-287). Quimper: European Commission, C2.

Gibson, A. M., Bratchell, H., \& Roberts, T. A. (1987). The effect of sodium chloride and temperature on rate and extent of growth of Clostridium botulinum type A in pasteurized pork slurry. $J$ Appl Bacteriol, 62(6), 479-490.

Giannuzzi, L. (1998). Mathematical modelling of microbial growth in fresh filled pasta stored at different temperatures. J Food Process Preserv, 22(6), 433-447.

Hayes, J. E., Stepanyan, V., Allen, P., O'Grady, M. N., \& Kerry, J. P. (2010). Effect of lutein, sesamol, ellagic acid and olive leaf extract on the quality and shelf-life stability of packaged raw minced beef patties. Meat Sci, 84(4), 613-620.

Horie, S., Tsutsumi, S., Takada, Y., \& Kimura, J. (2008). Antibacterial quinone metabolites from the brown alga, Sargassum sagamianum. Bull Chem Soc Jpn, 81(9), 1125-1130.

Hosokawa, M., Bhaskar, N., Sashima, T., \& Miyashita, K. (2006). Fucoxanthin as a bioactive and nutritionally beneficial marine carotenoid: a review. Carotenoid Sci, 10, 15-28.

Kim, Y. S., Hwang, C. S., \& Shin, D. H. (2005). Volatile constituents from the leaves of Polygonum cuspidatum S. et Z. and their antibacterial activities. Food Microbiol, 22(1), 139-144.

Lima-Filho, J. V. M., Carvalho, A. F. F. U., \& Freitas, S. M. (2002). Antibacterial activity of extracts of six macroalgae from the northeastern Brazilian coast. Braz J Microbiol, 33(4), 311-333.

Masuda, M., Abe, T., Sato, S., Suzuki, T., \& Suziki, M. (1997). Diversity of halogenated secondary metabolites in the red algae Laurencia nipponica (Rhodomelaceae Ceramiales). J Phycol, 33(2), 196-208.

Matsukawa, R., Dubinsky, Z., Kishimoto, E., Masaki, K., Masuda, Y., \& Takeuchi, T. (1997). A comparison of screening methods for antioxidant activity in seaweeds. $J$ Appl Phycol, 9(1), 29-35.

Mosqueda-Melgar, J., Raybaudi-Massilia, R. M., \& Martín-Belloso, O. (2008). Non-thermal pasteurization of fruit juices by combining high-intensity pulsed electric fields with natural antimicrobials. Innovative Food Sci Emerg Technol, 9(3), 328-340.

Nagayama, K., Iwamura, Y., Shibata, Y., Hirayama, I., \& Nakamura, T. (2002). Bactericidal activity of phlorotannins from the brown alga Ecklonia kurome. J Antimicrob Chemother, 50(6), 889-893.

Paul, V. J., \& Puglisi, M. P. (2004). Chemical mediation of interactions among marine organisms. Nat Prod Rep, 21, 189-209.
Plaza, M., Santoyo, S., Jaime, L., García-Blairsy Reina, G., Herrero, M., S noráns, F. J., et al. (2010). Screening for bioactive compounds from algae. J Pharm Biomed Anal, 51(2), 450-455.

Prashanth, D., Asha, M. K., \& Amit, A. (2001). Antibacterial activity of Punica granatum. Fitoterapia, 72(2), 171-173.

Salleh-Mack, S. Z., \& Roberts, J. S. (2007). Ultrasound pasteurization: The effects of temperature, soluble solids, organic acids and $\mathrm{pH}$ on the inactivation of Escherichia coli ATCC 25922. Ultrason Sonochem, 14(3), 323-329.

Sastry, V. M. V. S., \& Rao, G. R. K. (1994). Antibacterial substances from marine algae: Successive extraction using benzene, chloroform and methanol. Bot Mar, 37(4), 357-360.

Schenk, M., Guerrero, S., \& Alzamora, S. M. (2008). Response of some microorganisms to ultraviolet treatment on fresh-cut pear. Food Bioprocess Technol, 1(4), 384-392.

Taskin, E., Caki, Z., Ozturk, M., \& Taskin, E. (2010). Assessment of in vitro antitumoral and antimicrobial activities of marine algae harvested from the eastern Mediterranean Sea. Afr J Biotechnol, 9(27), 4272-4277.

Tiwari, B. K., O'Donnell, C. P., \& Cullen, P. J. (2009). Effect of non thermal processing technologies on the anthocyanin content of fruit juices. Trends Food Sci Technol, 20(3-4), 137-145.

Vairappan, C. C., Daitoh, M., Suzuki, M., Abe, T., \& Masuda, M. (2001). Antibacterial halogenated metabolites from the Malaysian Laurencia sp. Phytochemistry, 58(2), 291-297.

Xiong, R., Xie, G., Edmondson, A. S., Linton, R. H., \& Sheard, M. A. (1999). Comparison of the Baranyi model with the modified Gompertz equation for modelling thermal inactivation of Listeria monocytogenes Scott A. Food Microbiol, 16(3), 269-279.

Yuan, Y. V. (2008). Marine algal constituents. In C. Barrow \& F. Shahidi (Eds.), Marine nutraceuticals and functional foods (pp. 259-296). Boca Raton: CRC.

Zaragoza, M. C., Lopez, D., Saiz, M. P., Poquet, M., Perez, J., PuigParellada, P., et al. (2008). Toxicity and antioxidant activity in vitro and in vivo of two Fucus vesiculosus extracts. J Agr Food Chem, 56(17), 7773-7780.

Zárate-Rodríguez, E., Ortega-Rivas, E., \& Barbosa-Cánovas, G. V. (2000). Quality changes in apple juice as related to nonthermal processing. J Food Qual, 23(3), 337-349.

Zwietering, M. H., Jongenburger, I., Rombouts, F. M., \& Van'T Riet, K. (1990). Modelling of the bacterial growth curve. Appl Environ Microbiol, 56(6), 1875-1881. 


\section{AUTHOR QUERY}

\section{AUTHOR PLEASE ANSWER QUERY.}

Q1. Figures 1 and 3 has poor quality with pixelated image. Please provide better quality of the said figures. 